\title{
RANCANG BANGUN SISTEM KONTROL POSISI MEJA MESIN PLANER KAYU DENGAN PENGGERAK MOTOR STEPPER BERBASIS ARDUINO UNO
}

\author{
Muhammad Rafi Septiawan \\ Fakultas Teknik, Program Studi Teknik Mesin \\ Universitas Muria Kudus \\ Email: Muhammadraffiseptiawan17@gmail.com \\ Rochmad Winarso \\ Fakultas Teknik, Program Studi Teknik Mesin \\ Universitas Muria Kudus \\ Email: rochmad.winarso@umk.ac.id \\ Qomaruddin \\ Fakultas Teknik, Program Studi Teknik Mesin \\ Universitas Muria Kudus \\ Email: qomaruddin@umk.ac.id
}

\begin{abstract}
ABSTRAK
Permintaan akan teknologi terutama kebutuhan akan adanya mesin sekala kecil untuk menunjang kebutuhan industri rumahan yang membutuhkan mesin dengan desain simpel dan praktis dalam pengunaan maupun pengoprasian mesin. Dalam pengembangan mesin planer yang telah dibuat sebelumnya di perlukan penambahan sistem kontrol yang digunakan untuk mengatu posisi naik dan turun meja mesin planer kayu. Metode yang digunakan meliputi studi literatur, studi lapangan, desain sistem kontrol, perakitan hardware dan pengujian. Hasil penelitian adalah telah dibuat sistem kontrol untuk mengontrol posisi naik dan turun pada ketinggian meja mesin planer dengan pengerak motor stepper yang telah dikontrol mengunakan mikrokontroler berupa arduino uno didapatkan hasil keakuratan untuk naik maupun turun dengan minimal $1 \mathrm{~mm}$ dan maksimal $10 \mathrm{~cm}$ didapat nilai error sebesar $0,8 \%$
\end{abstract}

Kata kunci: mesin planer, motor stepper, sistem kontrol, arduino,

\begin{abstract}
The demand for technology requires the need for small scale machines to support the needs of home industries that require machines with simple and practical designs in the use and operation of machines. In the development of a pre-made plener machine on the required control system used to get up and down onto the table of wood planer machines. The method used contains literature studies, field studies, control system design, hardware installasion and testing.The results of the study, a control system has been made to go up or down at the height of the plener machine with the stepper motor driver which has been controlled using a microcontroller consisting of Arduino Uno obtained the accuracy to rise or rise with a minimum of $1 \mathrm{~mm}$ and a maximum of $10 \mathrm{~cm}$ obtained an error value of $0.8 \%$
\end{abstract}

Keywords: planer machine, stepper motor, control system, Arduino, 


\section{PENDAHULUAN}

Seiring berkembangnya zaman, kebutuhan akan teknologi mejadi semakin kompleks. Permintaan akan teknologi terutama kebutuhan akan ada nya mesin sekala kecil untuk menunjang kebutuhan industri rumahan yang membutuhkan mesin dengan desain simpel dan praktis dalam penggunaan maupun dalam pengoprasian mesin. Dalam dunia industri rumahan di butuhkan mesin planer kayu atau mesin serut kayu, bertolak dari mesin yang telah ada saat ini dalam industri meubel sekala rumahan, masih menggunakan serut kayu manual, yang biasa disebut ketam atau pasah yang pengoprasiannya masih mengunakan otot manusia, adapun mesin yang sedikit moderen masyarakat sering menyebut dengan istilah mesin serut kayu, yang sudah mengunakan mesin dalam pengoprasiannya, mesin serut ini masih memiliki banyak kekurangan mengenai ukuran yang kecil, dalam pengerjaan saat pemakanan menjadi terbatas. Blakangan ini mesin serut kayu semakin populer, keberadaan alat ini sangat memudahkan tukang kayu pada saat bekerja untuk menghaluskan permukaan kayu.

Mesin planer atau mesin serut berfungsi untuk membersihkan permukaan kayu dari cuttermark danmeratakan permukaan kayu sehingga seluruh permukaan sama tinggi dan menghaluskan permukaan kayu yang tidak rata agar proses finising kayu menjadi lebih mudah. Mesin serut ini di gunakan sebagai alat yang menunjang dalam industri furniture dari industri rumah tangga sampai industri skala besar. Mesin serut sangat membantu dalam memenuhi kebutuhan manusia yang terbuat dari bahan kayu[1].

Produsen luar negri yang menciptakan mesin-mesin serut kayu dengan berbagai jenis dari mesin wide belt sander, jointer, plener duduk, tapi semua itu belum bisa memenuhi kebutuhan industri kecil rumahan, karna harga mesin terlalu mahal dan funsi mesin itu lebih tepat digunakan untuk industri besar, oleh sebab itu perlu diciptakan mesin plener kayu otomatis. Prinsip kerja dari mesin planer kayu manual masih menggunakan tenaga manusia untuk mengatur ketinggian pada meja mesin planer, masih memutar ulir yang terhubung pada meja mesin planer, yang menimbulkan kurangnya keakuratan dalam mengatur ketinggian meja, yang berpengaruh saat pemakanan benda kerja. Maka dari itu dapat memanfaatkan teknologi yang saat ini sangat berpengaruh pada kehidupan sehari-hari. Meja mesin planer dioprasikan naik turun mengunakan sistem pemrograman mikrokontroler untuk mengatur putaran motor yang berfungsi untuk memutar ulir pada meja mesin planer.Perkembangan teknologi pada elektronik atau mikrokontroler saat ini untuk mengembangkan mesin planer kayu manual menjadi otomatis,

Rancang Bangun Sistem Kontrol Otomatis pada Meja Mesin Planer kayu dibutuhkan dalam inovasi mesin planer kayu otomatis ini yang berfungsi untuk mengontrol motor Stepper DC 1 phasa, dibutuhkan pengendali atau bisa disebut mikrokontroler yang berfungsi untuk mengatur atau memberikan perintah kepada driver motor yang selanjutnya driver motor meneruskan perintah ke motor stepper. Dalam mikrokontroler dibutuhkan juga program-program perintah untuk menghasilkan motor dapat berputar sesuai program . Mikrokontroler yang digunakan berbasis arduino uno[2].

Penelitian ini menempatkan mikrokontroler jenis Ardiuno Uno R3 untuk menggontrol putaran motor stepper untuk dapat mengatur posisi naik turun meja mesin planer kayu dan mengatur kecepatan putaran motor stepper, mengubah putaran motor stepper menjadi searah jarum jam dan berlawanan dengan jarum jam, mikrokontroler jenis Ardiuno Uno R3 sangat cocok untuk di tetapkan dalam mengatur meja otomatis pada meja mesin planer[3].

\section{METODOLOGI PENELITIAN}

Perancangan dan pembuatan sistem kontrol pada meja mesin planer kayu otomatis ini mengunakan tahapan-tahapan metodologi seperti yang terlihat pada diagram alir dibawah ini.Yang ditunjukkan pada gambar 1 dibawah ini 


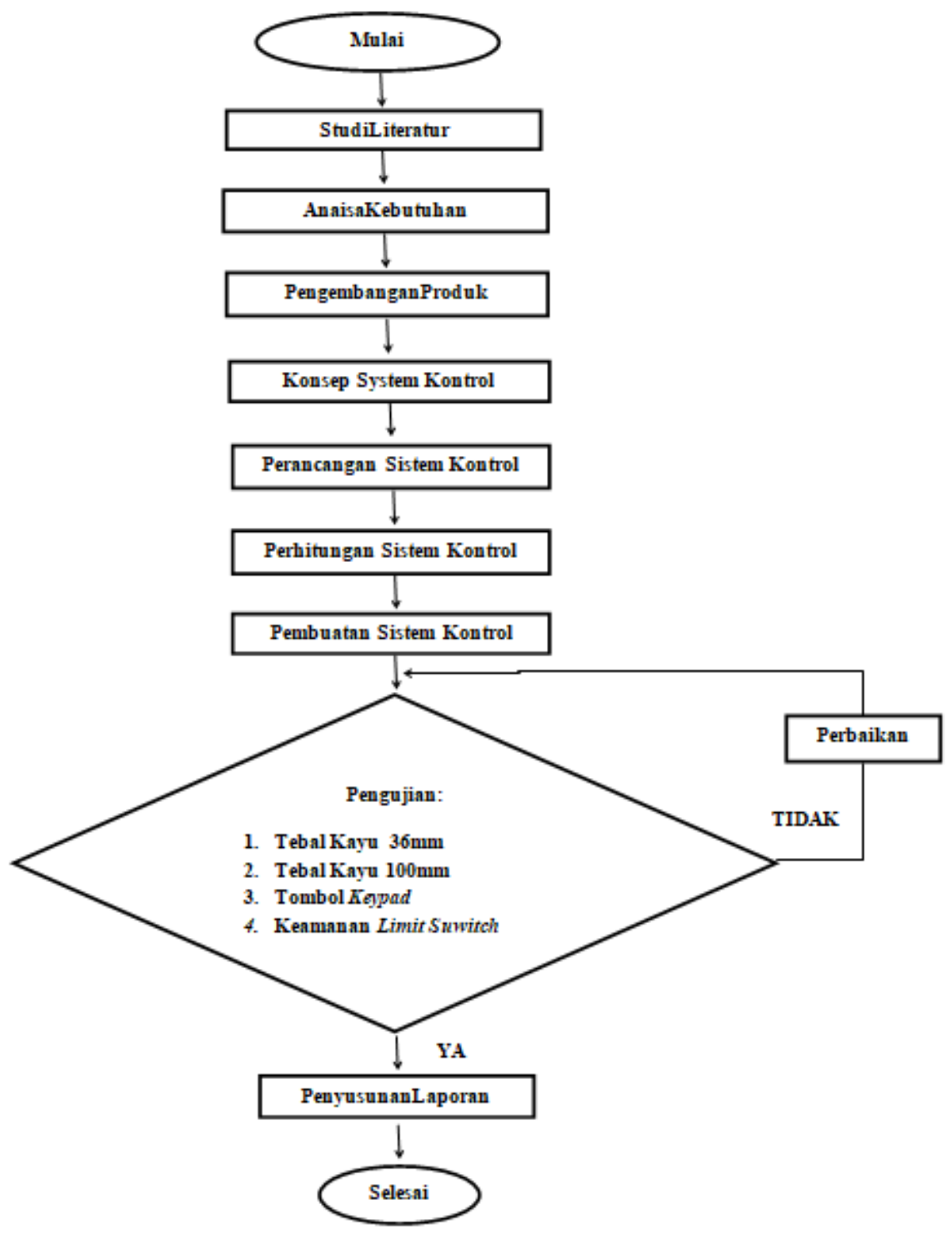

Gambar 2. Flowchart Penelitian 
Studi literatur meliputi kajian bahan pustaka yang berkaitan dengan segala permasalahan mengenai perencanaan rancang bangun sistem kontrol pada meja mesin planer kayu otomatis. Konsep design pada sistem kontrol dapat dilihat dari analisa kebutuhan, konsep sistem kontrol, perancangan sistem kontro, perancang software. Perhitungan sistem kontrol meliputi pulsa, rpm. Simulasi design bertujuan untuk menentukan rangkaian berjalan dengan sesuai konsep pada sistem ini menggunakan software proteus 8.0. Wiring dipergunakan untuk memberikan informasi mengenai rangkaian pengkabelan dari sistem montrol tersebut. Untuk wiring dapat dilihat pada gambar 2 dibawah ini

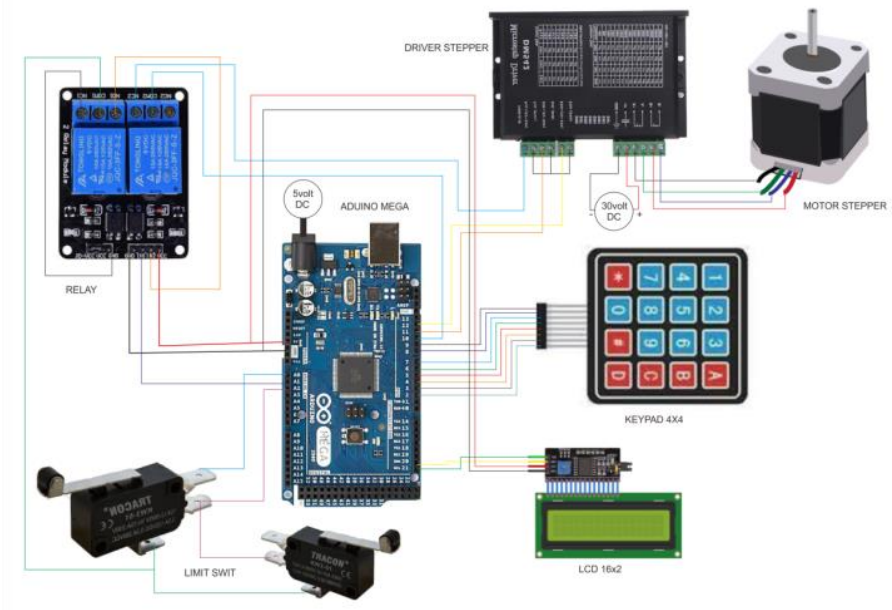

Keterangan:

Gambar 2 Wiring Rangkaian

1. Keypad

2. Arduino

3. $L C D$

4. Relay

5. Driver

6. Motor Stepper

7. Limit Switch

Prinsip kerja dari sistem kontrol pada meja mesi planer kayu otomatis:

1. Tekan slektor pada posisi ON

2. Rangkaian sistem kontrol otomatis kalibrasi pada posisi $10 \mathrm{~cm}$

3. Tekan angka pada keypad

4. Tekan (*) untuk menjalankan program perintah

\section{HASIL DAN PEMBAHASAN}

Kegiatan penelitian ini menghasilkan alat mesin plener kayu otomatis dengan maksimal pemakanan tebal $10 \mathrm{~cm}$ lebar lebar $24 \mathrm{~cm}$ panjang $80 \mathrm{~cm}$, dan minimal pemakanan $1 \mathrm{~cm}$ dengan sistem kontrol pada meja mesin planer mengunakan motor stepper berbasis arduino uno.

\subsection{Perhitungan Pulsa Motor}

Untuk merancang sistem kontrol pada naik turun meja otomatis ini perlu adanya perencanaan pulsa motor yang diperlukan agar sesuai dengan kebutuhan. Perencanaan yang diinginkan dengan motor stepper 400 pulsa/rotasi dan kecepatan pulsa masuk 1000 pulsa/detik, maka dapat direncanakan kecepatan putar motor[4]. Untuk perhitungan pulsa motor dan kecepatan putar motor mengunakan persamaan 1 sebagai berikut 


$$
\text { pps }=\frac{1000}{1}
$$

Kecepatan putar dapat dihitung mengunakan persamaan sebagai berikut:

$$
n=\frac{p p s}{N p}
$$

Hasil perhitungan jumlah pulsa motor stepper ditunjukkan pada tabel 1

Tabel 1. Hasil perhitungan jumlah pulsa motor

\begin{tabular}{lc}
\hline \multicolumn{1}{c}{ Perhitungan } & Hasil \\
\hline Kecepatan pulsa masuk & $1000 \mathrm{pps}$ \\
Kecepatan putar motor & $150 \mathrm{Rpm}$ \\
\hline
\end{tabular}

\subsection{Perhitungan Pulsa Yang di Input Dalam Program}

Pada perhitungan pulsa yang di butuhkan dalam pemrograman arduino uno dihitung dari hasil perhitungan roda gigi cacing. Yang di ketahui 35:1 yang artinya dalam 35 putaran poros ulir horizontal $=1$ putaran pada ulir vertikal, pada satu putaran ulir vertikal dapat naik maupun turun sebesar $5 \mathrm{~mm}$ sama dengan $360^{\circ}$. Jika yang kita butuhkan keakuratan dalam pemrograman maka untuk mencapai naik maupun turun $1 \mathrm{~mm}$ membutuhkan 7 putaran poros pada roda gigi cacing horizontal. Dengan perbandingan 7:1 yang artinya 7 putaran ulir horizontal $=1 \mathrm{~mm}$ yang dimaksud adalah dalam naik maupun turun $1 \mathrm{~mm}$ dibutuhkan putaran ulir vertikal dengan sudut $72^{\circ}$ Dapat dilihat di bawah ini mengenai perhitungan jumlah pulsa untuk untuk menaikkan meja setinggi $1 \mathrm{~mm}$ dan maksimal $10 \mathrm{~cm}$ sebagai berikut:

Jumlah pulsa terkecil yang terdapat pada program sebagai berikut:

Pulsa $=$ Np x Putaran motor stepper

Jumlah pulsa terbesar yang terdapat pada program sebagai berikut:

Pulsa $=$ Np x Putaran motor stepper

Hasil perhitungan pulsa ditunjukkan pada tabel 2:

Tabel 2. Hasil perhitungan jumlah pulsa pada program

\begin{tabular}{ll}
\hline \multicolumn{1}{c}{ Perhitungan } & Hasil \\
\hline Jumlah pulsa terkecil & 2800 Pulsa/rotasi \\
Jumlah pulsa terbesar & 280000 Pulsa/rotasi \\
\hline
\end{tabular}

\subsection{Pengujian dan Analisa Perangkat Keras}

Setelah semua komponen terpasang dan program selesai disusun dan di upload ke arduino, maka langkah berikutnya adalah melakukan pengujian alat. Pengujian ini dilakukan secara bertahap dari satu rangkaian ke rangkaian berikutnya.

\subsubsection{Pengujian Software}

Pengujian software dilakukan dengan mengamati respon alat pada saat program di masukkan (upload). Selain itu, pada saaat pembuatan program dilakukan proses verify atau compiling terlebih dahulu. Apabila terjadi kesalahan, maka akan muncul peringatan kesalahan pada bagian bawah tampilan program arduino. Pada saat terjadi kesalahan dalam pemprograman, tampilan peringatan kesalahanmuncul pada bagian bawah, tulisan pada bagian bawah menjadi berwarna kuning. Sedangkan apabila program yang dibuat berhasil, pada bagian bawah tampilan akan muncul tulisan berwarna putih. Untuk pemrograman yang benar dapat dilihat pada gambar 7 dibawah ini. 


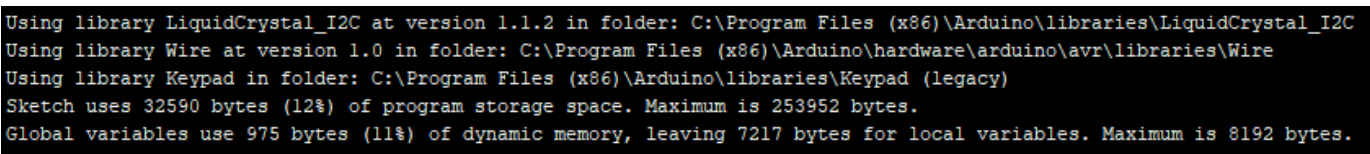

Gambar 7. Program Software Yang Benar

Dapat dilihat pada gambar 7, pada saat sebelum progran di upload dilakukan proses compiling yang berfungsi untuk melihat apakah ada program perintah atau pun program yang salah sebelum dilakukan upload pada arduino dapat dilihat pada gambar 8 dibawah ini.

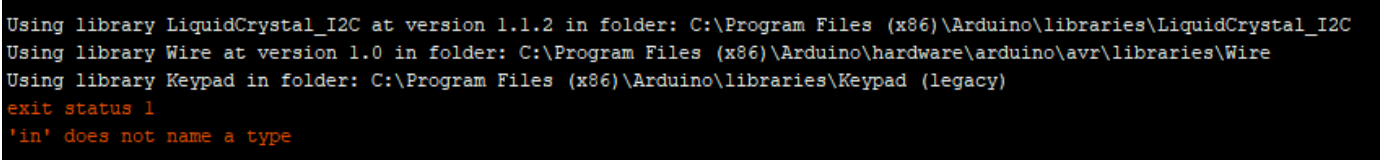

Gambar 8 Program Software Yang Salah

\subsubsection{Pengujian Sistem Kontrol}

Berikut ini adalah bentuk pengujian yang dilakukan penulis, dapat dilihat keakuratan program sistem kontrol yang bekerja pada mesin plener otomatis. Dilakukan pengujian mengunakan 2 benda kayu dengan tebal berbeda. [5] Untuk perhitungan hasil pengujian mengunakan persamaan sebagai berikut

Pengujian dengan tebal benda kerja $36 \mathrm{~mm}$.

Hasil pengujian 1 dapat dihitung mengunakan persamaan 5 sebagai berikut:

$$
\operatorname{Error}(\%)=\frac{(\mathrm{H} 0-\mathrm{H} 1)}{\mathrm{H} 1} \times 100 \%
$$

Hasil pengujian 2 dan 3 dapat dihitung mengunakan persamaan 5:

$$
\operatorname{Error}(\%)=\frac{(\mathrm{H} 0-\mathrm{H} 1)}{\mathrm{H} 1} \times 100 \%
$$

Tabel 3. Pengujian Pertama Dengan Ketebalan Benda Kerja Sebagai Berikut

\begin{tabular}{cccccc}
\hline $\begin{array}{c}\text { Tahap } \\
\text { Pengujian }\end{array}$ & Tombol & $\begin{array}{c}\text { Ketinggian yang } \\
\text { diinginkan } / \mathbf{m m} \\
(\mathbf{H 0})\end{array}$ & $\begin{array}{c}\text { Hasil } \\
\text { Pengujian/ } \\
\mathbf{m m}(\mathbf{H 1})\end{array}$ & $\begin{array}{c}\text { Error } \\
(\%)\end{array}$ & $\begin{array}{c}\text { Tampilan } \\
\text { LCD }\end{array}$ \\
\hline 1 & $36-6-*$ & 36 & 36,05 & $0,13 \%$ & 36 \\
2 & $3-6-*$ & 36 & 35,96 & $0,11 \%$ & 36 \\
3 & $3-6-*$ & 36 & $0 \%$ & 36 \\
\hline
\end{tabular}

Pengujian dengan tebal benda kerja $100 \mathrm{~mm}$.

Hasil pengujian 1, 2 dan3 dapat dihitung mengunakan persamaan 5 sebagai berikut: 


$$
\operatorname{Error}(\%)=\frac{(\mathrm{H} 0-\mathrm{H} 1)}{\mathrm{H} 1} \times 100 \%
$$

Hasil pengujian dengan ketebalan benda k erja 36 mm ditunjukkan tabel 4 :

Tabel 4. Pengujian Pertama Dengan Ketebalan Benda Kerja Sebagai Berikut

\begin{tabular}{cccccc}
$\begin{array}{c}\text { Tahap } \\
\text { Pengujian }\end{array}$ & Tombol & $\begin{array}{c}\text { Ketinggian yang } \\
\text { diinginkan } / \mathbf{m m} \\
(\mathbf{H})\end{array}$ & $\begin{array}{c}\text { Hasil } \\
\text { Pengujian/ } \\
\mathbf{m m}(\mathbf{H 1})\end{array}$ & $\begin{array}{c}\text { Error } \\
(\%)\end{array}$ & $\begin{array}{c}\text { Tampilan } \\
\text { LCD }\end{array}$ \\
\hline 1 & 36 & 36,05 & $0,13 \%$ & 36 \\
2 & $3-$ 3-* $^{*}$ & 36 & 35,96 & $0,11 \%$ & 36 \\
3 & $3-6-*$ & 36 & 36 & $0 \%$ & 36 \\
\hline
\end{tabular}

\subsection{Pengujian seluruh Sistem}

Pengujian rangkaian arduino ini menggunakan software proteus 8 propesional. Proteus adalah sebuah software untuk mendesain PCB yang juga dilengkapi dengan simulasi pspice pada level skematik sebelum rangkaian skematik diupgrade ke PCB shingga sebelum PCB nya di cetak kita akan tahu apakah PCB yang akan kita cetak sudah benar atau tidak. Proteus mengkombinasikan program ISIS untuk membuat skematik desain rangkaian dengan program ARES untuk membuat layout PCB dari skematik yang kita buat. Software ini bagus digunakan untuk desain rangkaian mikrokontroller. Pengujian pada software ini di desain menyerupai bentuk rangkaian pada sistem kontrolnya. Untuk gambar rangkaian sistem kontrol menggunakan sofware proteus 8.0 dapat dilihat pada gambar 9 dibawah ini.

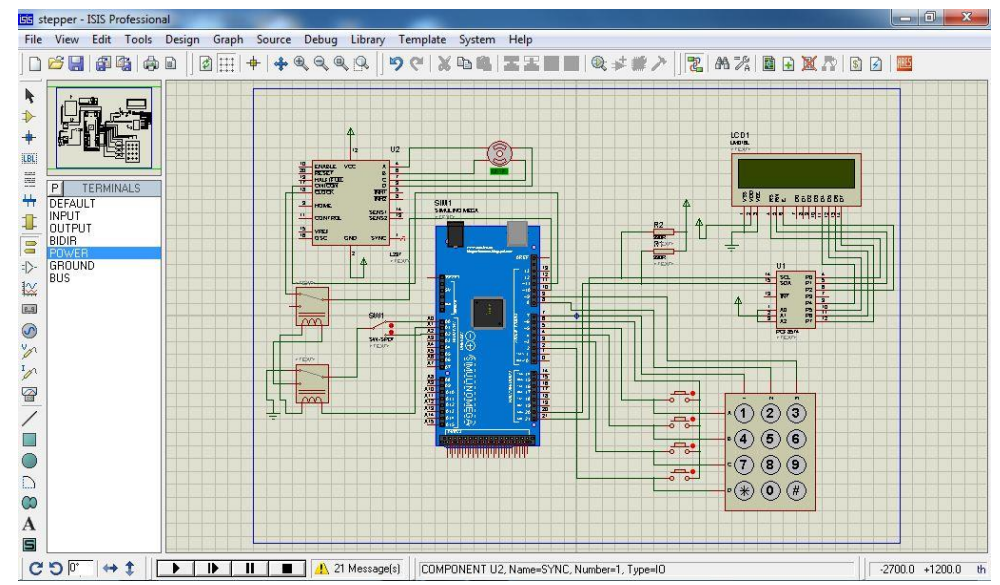

Gambar 9 Rangkaian Sistem Kontrol Mengunakan Sofware Proteus 8.0

\section{KESIMPULAN}

Dari racang bangun sistem kontrol posisi meja mesin planer kayu otomatis dengan menggunakan penggerak motor stepper berbasis arduino uno dapat di ambil kesimpulan sebagai berikut: 
1. Telah dibuat sistem kontrol naik turun meja mesin planer kayu secara otomatis berbasis mikrokontroler arduino uno yang dapat bekerja sesuai standar mesin planer kayu, yaitu mampu bekerja secara presisi dalam mengatur ketinggian posisi meja dari mulai $1 \mathrm{~mm}$ hingga sampai $10 \mathrm{~cm}$.

2. Rangkaian sistem kontrol posisi naik dan turun meja menggunakan motor stepper yang di kendalikan menggunakan mikrokontroler berbasis arduino uno untuk mengerakkan poros roda gigi cacing.

3. Hasil pengukuran keakuratan rangkaian sistem kontrol masih menggunakan pengaris manual yang nilai keakuratan harus di ukur ulang dengan jangka sorong digital, dan didapat nilai error sebanyak $0,8 \%$

4. LCD hanya menampilkan posisi meja pada saat anggka yang di input ke program, karna tidak adanya sesnsor alat ukur maka LCD tidak bisa membaca sepertihalnya sensor jarak.

\section{DAFTAR PUSTAKA}

[1] R. Setiawan, 2014 "Mesin Serut Kayu Semi Otomatis Dengan Penggerak Motor Listrik Dengan Penggerak Motor Listrik,"

[2] R. Y. Nasution, H. Putri, and Y. S. Hariyani, 2015 "Perancangan Dan Implementasi Tuner Gitar Otomatis Dengan Penggerak Motor Servo Berbasis Arduino," J. Elektro Telekomun. Terap. Juli 2015, pp. 83-94.

[3] S. Huda, "Hasil pemotongan pada mesin press dan pemotong kantong plastik dengan kapasitas 500 pcs / jam," pp. 1-8, 2018.

[4] P. P. Kalatiku and Y. Y. Joefrie, 2011 "Pemrograman Motor Stepper Dengan Menggunakan Bahasa Pemrograman C," no. 20 September 2015,

[5] M. R. Azhari, 2017 "Perancangan Mesin Pemarut Dan Pemeras Umbi Ganyong (Canna Discolor) Dengan Kapasitas $50 \mathrm{Kg} / \mathrm{Jam}$," Universitas Muria Kudus.. 